\title{
SÔBRE O ENCONTRO DE MAIS SETE CASOS DE MOLÉSTIA DE CHAGAS NO MUNICÍPIO DE ITAPORANGA (ESTADO DE SÃO PAULO) (*)
}

SAMUEL B. PESSOAA

(Do Depart. de Parasitologia)
F. OLIVEIRA LIMA

(Do Depart. de Saúde)

\section{ALVES DOS SANTOS}

(Do Depart. de Saúde)

Relatamos na presente nota o achado de mais sete casos humanos de moléstia de Chagas, sendo quatro de forma aguda e três crônica, no Núcleo Colonial "Barão de Antonina”, Município de Itaporanga, Estado de S. Paulo.

A localidade em que ora são verificados êstes casos já havia sido objeto de vários inquéritos epidemiológicos sôbre moléstia de Chagas.

Assim Pessôa, em princípios de 1940, em viagem que fez ao Núcleo, capturou alguns exemplares de Triatoma infestans, os quais, examinados por Cardoso e Navajas (1), mostraram estar infectados pelo T. cruzi. Em julho de 1940 êstes dois autores (1), no referido Núcleo Colonial, pelo exame de 540 insetos, determinaram a elevada percentagem de infecção de $45,3 \%$. Foram também, na mesma época, encontrados dois casos de infecção natural de cães pelo $T$. cruzi.

Em inquérito posterior, Cardoso, Navajas e Alves dos Santos (2) descreveram os dois primeiros casos agudos da moléstia no homem. Coutinho (3), na mesma localidade, em 1941, examinou 50 pessôas aí residentes, indiscriminadamente, moradoras em casas com triatomas infectados e encontrou quatro com Trypanosoma cruzi no sangue periférico, o que dá a percentagem de 8\% de doentes. Em 1942, F. Oliveira Lima e I. Alves dos Santos (4) descreveram 3 casos de forma aguda e I. Alves dos Santos e F. A. Cardoso um outro caso também de forma aguda.

Por êste rápido sumário pode-se ver como são frequentes casos humanos da tripanosomose de Chagas na localidade em aprêço; assim resolvemos também noticiar mais sete casos novos, pensando que estas

(*) Lido na Sessão de 9-9-42 da Associação Paulista de Medicina (Secção de Higiene e Moléstias Infecciosas e Tropicaia). 


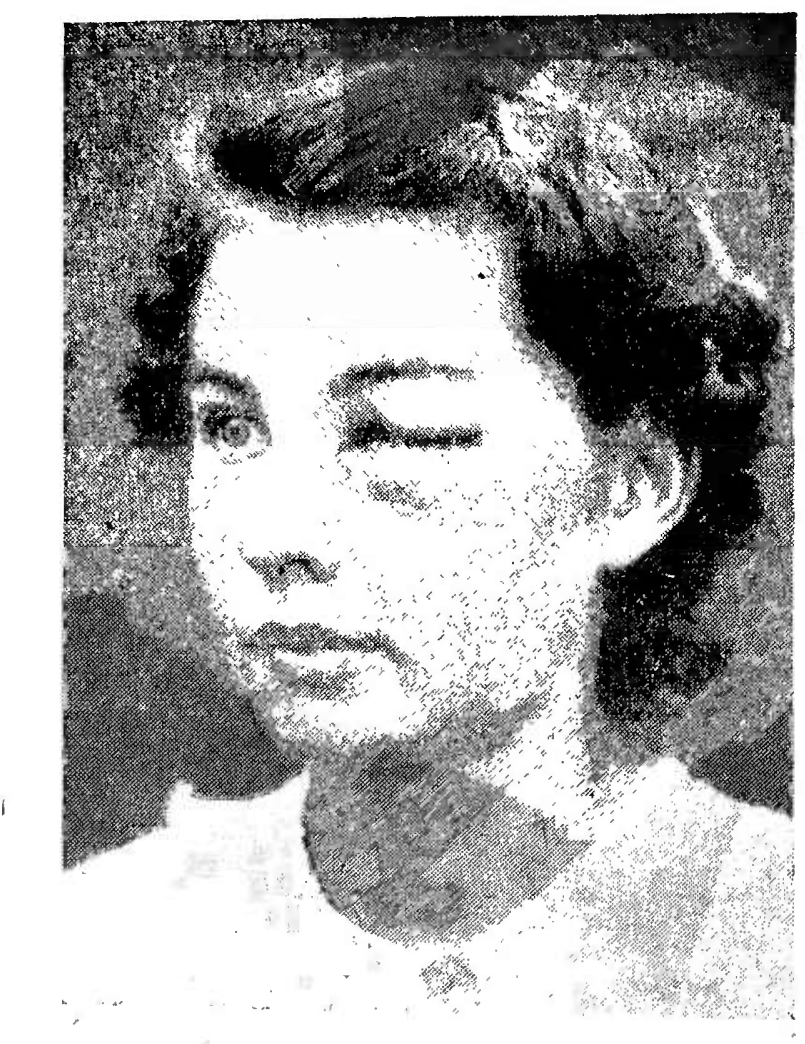

Obs. 1 - E. T. $\underset{\text { tia }}{\text { FIg. } 1}$ Caso agudo de Molés-

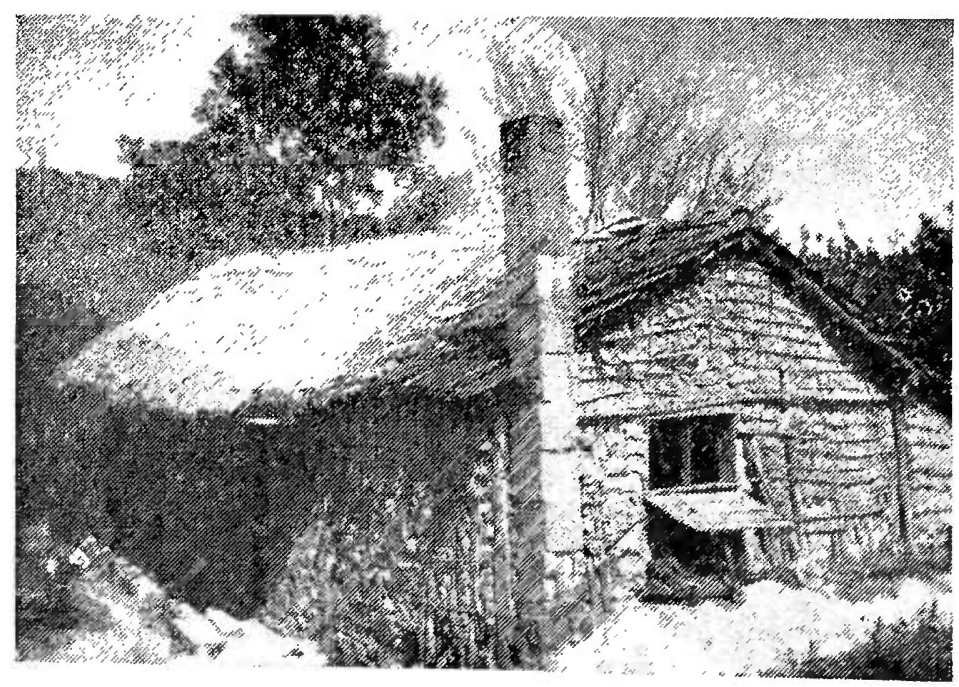

Residência de E. T. - Fig. 2 de pau-a-pique barreada, com grande número de triatomas. 
observações levarão, sem dúvida, as nossas autoridades sanitárias a encarar com decisão êste importante problema de higiene rural.

\section{OBSERVAÇÕES DOS CASOS}

\section{a) Formas agudas.}

(1) E. T. - Sexo feminino, branca, brasileira, solteira, com 18 anos de idade, natural do Distrito Federal. Residência atual: Núcleo Colonial "Barão de Antonina".

Doença atual: Veio à consulta a 27 de maio. Fazia três semanas que, sem outra manifestação qualquer, sentia inchado o olho esquerdo.

Exame físico: Blefaro-conjuntivite sem secreção alguma. Grande edema roseo bipalpebral do olho esquerdo, muito mais acentuado na palpebra inferior (Fig. 1). Ganglios pre-auriculares, sub-angulo-maxilares e sub-maxilares aumentados. Temperatura - $37^{\circ}, 3 \mathrm{C}$. Pulso - de pé: 100 batimentos; deitada: 94. Pressão: Mx. 13 e Mn. 7. Baço palpavel dois dedos abaixo do rebordo costal à inspiração profunda.

\section{Exames de laboratório:}

Ex. de fézes - Negativo.

Ex. de urina - Normal.

Gota espessa - Raros Trypanosoma cruzi.

Xénodiagnostico - Positivo.

Formula leucocitária (Dr. Nelson V. de Barros):

\begin{tabular}{|c|c|}
\hline Mieloblastos & 0.8 \\
\hline Mielocitos & \\
\hline Jovens ... & 0.0 \\
\hline Bastonetes & 16.4 \\
\hline Segmentados & 36. \\
\hline Eosinofilos & \\
\hline Basofilos & \\
\hline Linfocitos típicos $\ldots \ldots \ldots \ldots \ldots \ldots \ldots \ldots \ldots$ & 26.8 \\
\hline 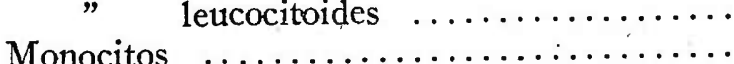 & \\
\hline $\begin{array}{l}\text { Monocitos } \\
\text { Elementos } \text { plasmáticos } \ldots \ldots \ldots \ldots \ldots \ldots \ldots \ldots\end{array}$ & \\
\hline
\end{tabular}

Observações: Grande quantidade de granulações tóxicas nos neutrofilos. Evidente hipocromia.

(2) G. B. - Sexo feminino, brasileira, solteira, com 16 anos de idade. Residente em Samambaial (Município de Itaporanga), em casa de madeira e pau-a-pique, 'barroteada, com piso de chão e coberta de sapé. Em sua casa encontramos grande quantidade de "barbeiros".

Queixa: Veiu à consulta em 24 de maio. Estava doente há 8 dias, com febre, dor de cabeça e edema palpebral direito. (Fig. 3).

Exame físico: Peso - $64 \mathrm{kgs}$. Altura - 1,61 cms. Temperatura $37^{0}, 5$. Apresentava grande edema, mole, roseo, bipalpebral direito, muito mais acentuado na palpebra inferior, e que atingia as regióes malar, geniana e maxilar inferior. Ganglio pre-auricular direito, doloroso, volumoso, do tamanho de uma azeitona. Ganglios sub-angulo-maxilares e sub-maxilares do lado direito aumentados de volume. Também notava-se a presença de ganglios supraclaviculares e cervicais (retro-sterno-cleido) aumentados do lado direito. Do 
laclo esquerdo os ganglios se apresentavam normais. Conjuntiva ocular congestionada. Glandula lacrimal aumentada de volume, sem aumento da secreção lacrimal, e sem secreção purulenta. Dentes em bom estado. Ligeira hipertrofia das amigdalas. Coração e pulmão normais. Pulso - de pé: 128 batimentos. Pressão - Mx. 12, mn. 6. Baço não palpavel. Apresentava uma lesão (chagoma?) regularmente circular, de $5 \mathrm{cms}$. de diametro, na face anterior da articulação tibio-tarsica esquerda. Não havia dor nem secreção nem prurido. A pele era esfoliada, aspera, como se apresenta num eczema seco. Os bordos ligeiramente mais salientes e levemente dolorosos. $\mathrm{O}$ aspecto geral lembrava o de uma placa micótica, que desapareceu sem medicação local alguma.

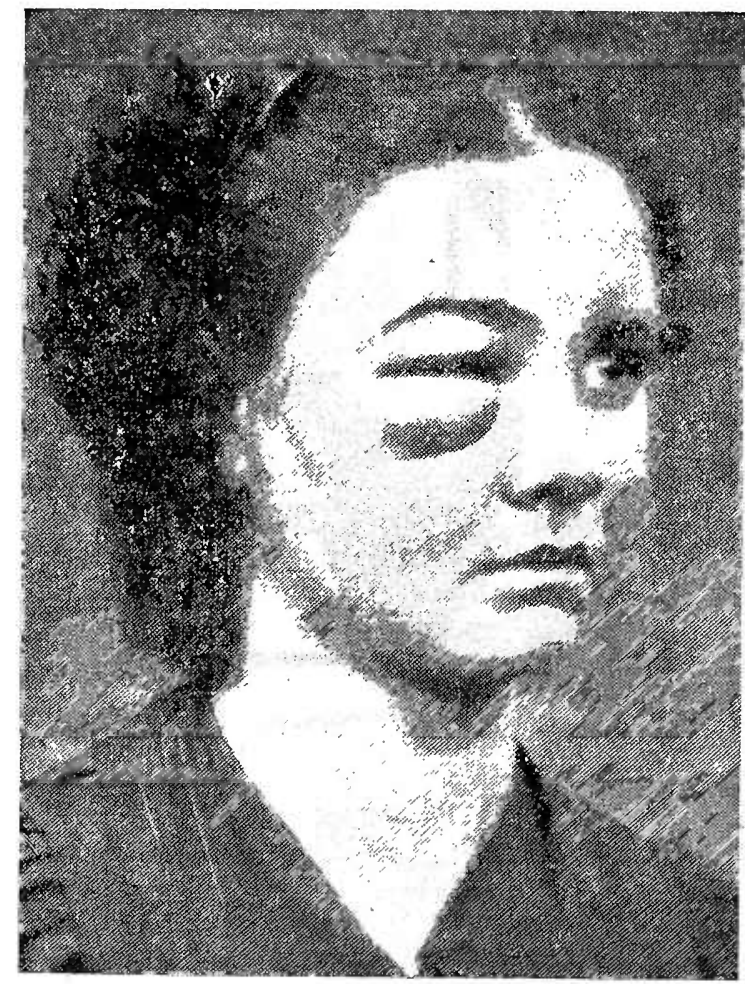

FIG. 3

Obs. 2 - G. B. - Caso agudo de Moléstia de Chagas.

Exames de laboratório:

Ex. de fézes - Negativo.

E.x. de urina - Presença de fosfatos.

Gota espessa - Feito em 24-V-42 - Negativo.

Xenodiagnostico - Positivo (em 24-V-42). Negativo (em 2-X-42). Formula leucocitária (Dr. Nelson V. de Barros):

Mieloblastos

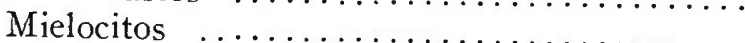

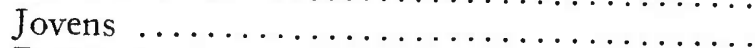

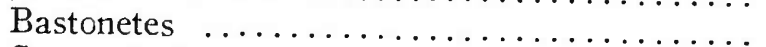

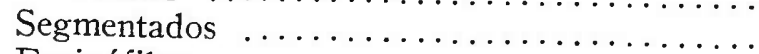

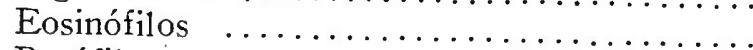

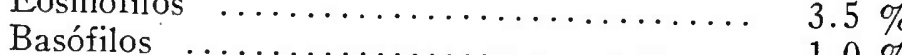

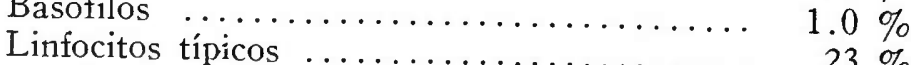

............... $23 \%$

leucocitoides $\ldots \ldots \ldots \ldots \ldots \ldots .3 .5 \%$ 


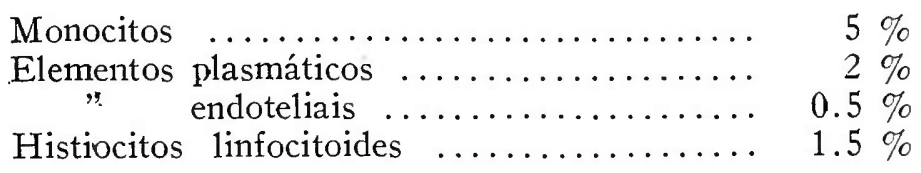

Observações: Neutrófilos apresentando grande quantidade de granulações tóxicás. Evidente hipocromia.

(3) A. de O. - Sexo masculino, branco, brasileiro, solteiro, com 15 anos de idade, lavrador, residente na fazenda do Gaspar, em Ribeirão Vermelho (Município de Itaporanga). Reside em casa de pau-a-pique, mal barroteada, com piso de.soalho e coberta de telha.

Queixa: Veiu à consulta no principio de junho, já com dez dias de doença, queixando-se de dores pelo corpo, febre, grande fraqueza e edema palpebral direito. (Fig. 4).

Exame físico: Peso - 46,700 kgs. Altura - 1,56 cms. Temperatura $38^{\circ}$,4. Grande edema bipalpebral do lado direito, roseo e levemente turgido, muito mais acentuado na palpebra inferior, alcançando a região malar. Dacroadenite direita. O ganglio pre-auricular direito aumentado, com $2 \mathrm{cms}$. no seu diametro maior. Ganglio retro auricular direito volumoso, com $3 \mathrm{cms}$. no seu diametro maior. Um grande ganglio axilar direito. Infartamento bilateiral dos ganglios inguino-crurais. Pulso - de pé: 114 batimentos. Deitado: 102. Baço palpavel.

\section{Exames de laboratório:}

$$
\begin{aligned}
& \text { Ex. de fézes - Negativo } \\
& \text { Ex. de urina - Normal. } \\
& \text { Gota espessa - Positiva. } \\
& \text { Xenodiagnostico - Positivo (11-VIII-42). }
\end{aligned}
$$

(4) E. V. M. - Sexo masculino, brasileiro, pardo, com 16 anos de idade, operário de Turma de Saneamento, residente no lote 58 do Núcleo Colonial "Barão. de Antonina". Mora em casa de pau-a-pique, barroteada, coberta de sapé, com piso de chão, onde há grande quantidade de "barbeiros". Nasceu em Gavião Peixoto, onde morava em casa de tabôa, e faz dez anos que veiu para o lote n. $^{\circ} 58$ do Núcleo.

Queixa: Não veiu à consulta. Vimo-lo trabalhando na turma de saneamento, e pelo edema do olho direito e da face suspeitamos tratar-se de mais um caso agudo do mal de Chagas. Temperatura - $38^{\circ}, 2$.

Doença atual: Adoeceu no dia 22 de março, com dor nas pernas, raquialgia, cefaléia, quando também percebeu o edema do olho e da face, do lado direito e grande aumento do ganglio sub-angulo-maxilar direito.

Antecedentes pessoais: Registra-se no seu passado varicela, coqueluche, parotidite infecciosa e gripe.

Antecedentes familiares: Pais vivos e sadios. 7 irmãos também sadios.

Exame físico: Altura - $1,58 \mathrm{cms}$. Peso - $39 \mathrm{kgs}$.

Cabeça: Edema roseo bipalpebral, de ambos os olhos, muito mais acentuado do lado direito, e principalmente das superiores (Fig. 5). Edema da face direita, nas regiões malar e geniana. Blefaro conjuntivite congestiva bilateral, sem secreção alguma. Glandulas lacrimais aparentemente indenes. Tiroide - Bocio difuso homogeneo, não muito grande. Ganglios linfáticos Ganglios pre-auriculares volumosos, moveis, duros e indolores, do tamanho de es lados. Ganglio sub-maxilar direito enorme, do ta- 
manho de uma noz, duro, movel e indolor. Ganglio sub-angulo-maxilar aumentado à direita, e apenas palpavel à esquerda. Dois ganglios volumosos e centrais no assoalho da lingua. Ganglios ocipitais muito grandes. Ganglios supraclaviculares volumosos e palpaveis dos dois lados. Ganglios axilares enormes, e ganglios epitrocleanos muito grandes. Ganglios inguino-crurais, principalmente os crurais, muito aumentados, tendo o maior um diametro de cerça de $4 \mathrm{cms}$. Ganglio da fossa iliaca aumentados dos dois lados. direito.

Boca: Amigdalite lacunar hipertrofica. Ausência de um incisivo superior

Torax: Aparelho respiratório - nada de importante. Aparelho circulatório - Choque da ponta no $4 .^{\circ}$ espaço, $3 \mathrm{cms}$. para dentro da linha mamilar. Sopro anemico da $1 .^{\mathrm{a}}$ bulha aortica. Pulso, com 96 batimentos, deitado, e 120, de pé. Pressão arterial - Mx. 11 1/2 Mn. 6.

Abdomen: Baço - não palpavel, nem percutivel. Figado - normal. Sistema nervoso - Babinsky presente do lado direito. Ausência do cremasterino direito.

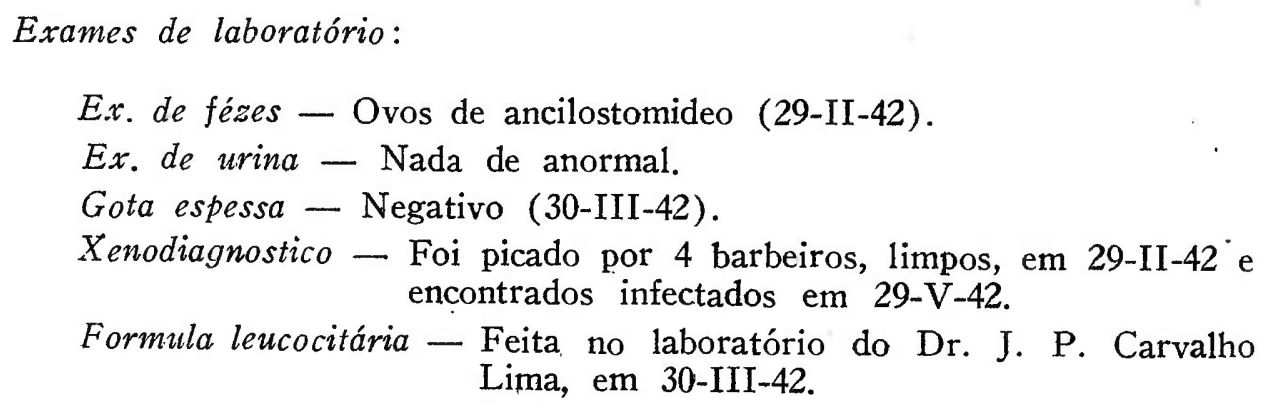

Eosinófilos $\quad \ldots \ldots \ldots \ldots \ldots \ldots \ldots \ldots \ldots \ldots \ldots \ldots \ldots$
Basófilos $\ldots \ldots \ldots \ldots \ldots \ldots \ldots \ldots \ldots \ldots$

Hematias: Coloração e tamanho normais; poicilocitose discreta.

Leucocitos: Linfocitose acentuada, neutropenia com desvio à esquerda, bastonetose.

\section{b) Formas crônicas.}

(5) A. A. A. - Sexo feminino, branca, brasileira, com $3 \cdot 1 / 2$ anos de idade, residente no lote 40 do Núcleo Colonial "Barão de Antonina". Mora -em casa de pau-a-pique, barroteada, coberta de sapé, e com piso de chão. $€$ filha de B. A. A. e irmã de J. A. A. (ambos chagasicos).

Doença atual: No dia 28 de fevereiro sua mãe percebeu que A. A. A. tinha um edema bipalpebral no olho direito, com diminuição da fenda palpebral, e estava sub-febril. Temperatura - $37^{\circ}$.

Antecedentes pessoais: Já é a segunda vez que lhe aparece ese edema das palpebras, sendo a primeira vez em outubro de 1941. Seus pais não se lembram se o edema bipalpebral foi no mesmo olho. Teve parotidite infecciosa.

Exame físico: Peso - $16 \mathrm{kgs} .200$. 


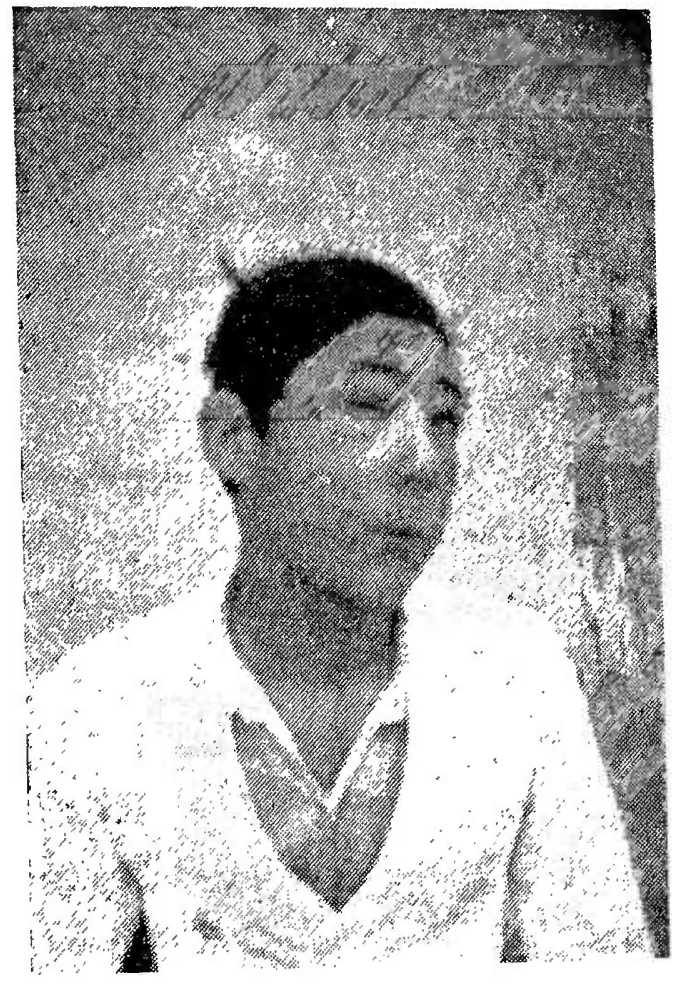

Fig. 4

Obs. 3 - A. de O. - Caso agudo de Moléstia de Chagas.

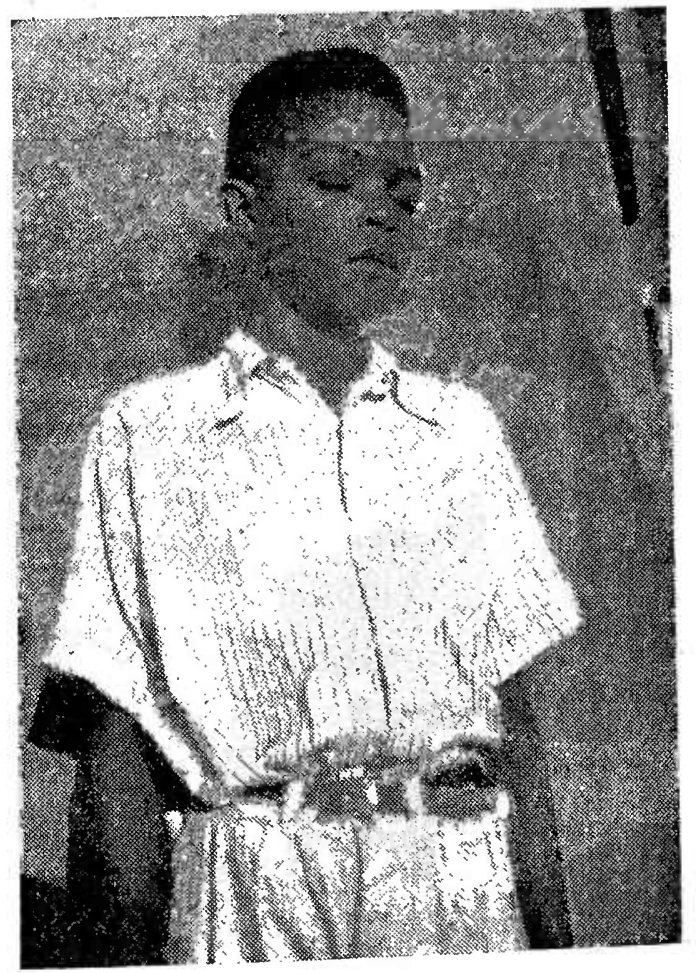

FIG. 5

Obs. 4 - E. V. de M. - Caso agudo de Moléstia de Chagas. 
Cabeça: Ligeiro edema bipalpebral, com diminuição da fenda, que se desfez em poucos dias. Tiroide - normal. Ganglios linfáticos - Ganglio submaxilar volumoso dos dois lados, principalmente do lado direito. Ganglios epitrocleanos volumosos dos dois lados. Axilares aumentados dos dois lados.

Torax: Aparelho respiratório - nada de anormal. Aparelho circulatório - Choque da ponta no $4 .^{\circ}$ espaço sôbre a linha mamilar. Ritmo fetal. Taquicardia. Pulso, 120 batimentos, de pé, e deitada, 110.

Abdomen: Baço - normal. Figado - normal.

Exames de laboratório:

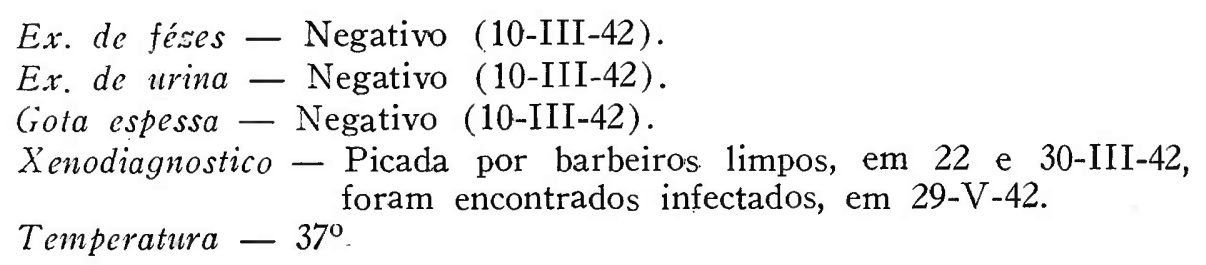

(6) B. A. A. - Sexo masculino, com 35 anos de idade, moreno, brasileiro, casado, lavrador, residente no lote 120 do Núcleo. Natural de Taquari. Sempre morou em casa de pau-a-pique, barroteada, coberta de sapé e com piso de chão.

Antecedentes pessoais: Registra no seu passado, sarampo, coqueluche, impaludismo em 1941 e 42. Várias vezes teve o edema bipalpebral dos dois olhos sempre acompanhado de raquialgia, mialgia e cefaléa.

Antecedentes familiares: Casado duas vezes, tem 5 filhos, todos mais ou menos sadios a-pesar-de castigados pela malária e verminose. Em três dos filhos já se confirmou a moléstia de Chagas, sendo dois de forma aguda e um crônica. A mulher e os outros dois filhos são bem suspeitos, merecendo a repetição dos exames pelo método da gota espessa e principalmente pelo xenodiagnostico.

Queixa: No dia 18 de fevereiro conta que teve um acesso de maleita, quando também se apresentou um ligeiro edema dos olhos, dor nas cadeiras e nas pernas. Teve três acesos de malária sem tomar remedio. Depois tomou quinino.

Doença atual: Vimo-lo no dia 28-II-42. Procurou o Hospital por causa da malária. Temperatura - $37^{\circ}, 4$. Apresentava ligeiro edema da palpebra inferior, de ambos os olhos. Como seu filho se apresentasse com forma aguda do mal de Chagas, resolvemos fazer exame de todas as pesoas da família, por nos parecerem suspeitas.

Exame físico: Altura - 1,75 cms. Peso - $68 \mathrm{kgs}$.

Cabeça: Olhos - ligeiro edema da palpebra inferior nos dois olhos. Ganglios linfáticos - Ganglios sub-maxilares aumentados, do tamanho de um caroço de azeitona, em ambos os lados. Ganglios cervicais e supra-claviculares dos dois lados formando cadeia, e se apresentando do tamanho de um feijão. Ganglios epitrocleanos volumosos dos dois lados. Ganglios inguino-crurais aumentados de volume dos dois lados.

Torax: Coração - Choque da ponta no $50^{\circ}$ espaço, na linha mamilar. Pressão arterial - Mx. 12, Mn. 7 1/2. Pulso, com 94 batimentos, de pé, $\epsilon$ 84, deitado.

Abdomen: Baço - aumentado, um dedo abaixo do rebordo costal. Sistema nervoso - reflexos rotulianos diminuidos. A temperatura, nas muitas vezes que tivems ocasião de ve-lo durante um mês, ocilou entre $37^{\circ}$ e $37^{\circ} 4$. 


\section{Exames de laboratório:}

Ex. de fézes - Ovos de ancilostomideo (10-III-42).

Ex. de urina - Nada de anormal (10-III-42).

Gota espessa - Negativo (9-III-42).

Xenodiagnostico - Positivo - picado por 5 barbeiros limpos, em 9-III-42, foram encontrados infectados em 29-V-42.

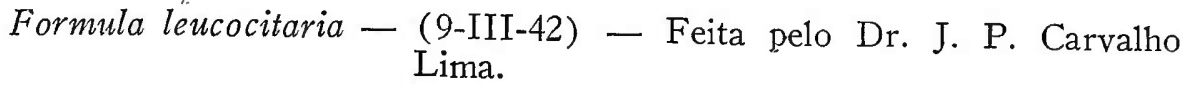

\begin{tabular}{|c|c|c|}
\hline Eosinófilos & & $10 \%$ \\
\hline Basofilos . & & $0,5 \%$ \\
\hline & Mielocitos $\ldots .$. & \\
\hline Neutrófilos & Bastonetes $\quad \ldots \ldots \ldots \ldots \ldots \ldots$ & $\begin{array}{l}0,0 \\
4,0\end{array}$ \\
\hline Linfo & Segmentados & 49,0 \\
\hline Lon & ........ & 05 \\
\hline โão & $\cdots$ & 1 \\
\hline
\end{tabular}

Hematias: Tamanho e aspecto normais. Bem coradas.

Leucocitos: Eosinofilia, neutropenia, ligeira linfocitose.

(7) B. M. J. - Sexo feminino, morena, brasileira, com 12 anos de idade, residente no lote 120 do Núcleo, morando sempre em casa de pau-a-pique, barroteada, coberta de sapé, com piso de chão. Nasceu em Barra Grande, Município de Itaporanga.

Antecedentes pessoais: Teve sarampo, coqueluche, parotidite infecciosa e malária de fevereiro a julho de 1941.

Antecedentes familiares: Pai e dois irmãos com mal de Chagas, positivados um pelo exame de gota espessa e dois pelo xenodiagnostico. Mãe e outros irmãos suspeitos da mesma doença.

Doença atual: Não veiu à consulta. Com a comprovação do laboratório da moléstia de Chagas em um seu irmão, suspeitamos da existência de outros casos na familia.

Exame físico: Altura - 1,38 cms. Peso - $301 / 2 \mathrm{kgs}$. Ganglios linfáticos - Ganglios pre-auriculares, bilaterais, do tamanho de um grão de feijão, moveis, duros e indolores. Retro-auricular esquerdo do tamanho de uma azeitona. Ganglio angulo maxilar aumentado, do tamanho de uma azeitona, só do lado esquerdo. Ganglio sub-maxilar direito, aumentado, e com o dobro do volume do da esquerda. Rede ganglionar cervical bastante aumentada do lado direito e apenas sensivel à esquerda. Enormes ganglios epitrocleanos. Ganglios inguinocrurais muito grandes.

Torax: Aparelho circulatório - Choque da ponta no $4 .^{\circ}$ espaço, na linha mamilar. Sopro sistólico da $1 .^{\mathrm{a}}$ bulha no foco.mitral (anemico). Pulso, com 108 batimentos, de pé, e 96, deitada.

\section{Exames de laboratório:}

Ex. de fézes - Negativo (22-III-42).

Ex. de urina - Nada de importante.

Gota espessa - Negativo (12-III-42).

Xenodiagnostico - Positivo - Picada por três barbeiros limpos, em 22-III-42, foram encontrados infectados em $29-\mathrm{V}-42$.

\section{RESUMO}

Os A. A. relatam mais sete casos de moléstia de Chagas no Município de Itaporanga, Estado de S. Paulo. Quatro observações 
eram da forma aguda, todos êles apresentando o complexo oftalmoganglionar (sinal de Romaña ou de Chagas-Romaña). Dois demonstraram o $T$. cruzi por meio de gota espessa de sangue e,en todos os quatro o xenodiagnóstico foi positivo. Três casos eram da forma crônica e todos êles apresentavam história clínica de moléstia de Chagas. O exame de sangue usando o processo da gota espessa em todos foi negativo, porém o xenodiagnóstico sempre se mostrou positivo.

Os A. A. chamam novamente a atenção sôbre a importância sanitária desta parasitose no Estado de S. Paulo.

\section{BIBLIOGRAFIA}

1 - Cardoso, F. A. e Navajas, E. - 1941. - Achado de dois cães naturalmente infectados pelo Trypanosoma cruzi Chagas, 1909 no Município de Itaporanga, Estado de S. Paulo.

2 - Cardoso, F. A., Navajas, E. e Alves dos Santos, I. - 1941. - Dois casos de forma aguda de moléstia de Chagas, encontrados no Município de Itaporanga, Estado de S. Paulo. - Rev. Clin. de S. Paulo - X (2) : 50-53.

3 - Coutinho, J. O. - 1941. - Dados epidemiológicos sôbre a Doença de Chagas em uma zona restrita do Estado de. S. Paulo. - Rev. do Inst. "Adolfo Lutz" - 1 (2) : 381-388.

4 - Lima, F. Oliveira e Alves dos Santos, I. - 1942. - Três casos de forma aguda da moléstia de Chagas, no Município de Itaporanga, Estado de S. Paulo. - Acta Medica - X (1) : 17-26.

\section{Preparados F a r m a c ê ut i c o s}

Temos a venda Marcas e Formulas licenciadas e incumbimo-nos de sua compra, venda, ou registro. LICENCIAMOS FORMULAS, PODENDO SER EXAMINADAS POR NOSSO TECNICO FARMACEUTICO OU FORNECER FORMULAS. Legalizamos Laboratorios Farmaceuticos, fazemos quaisquer contratos, de instalação, de exploração, de propaganda, de fabricação.

C O N S U L T E M - N OS SEM COM P R OMIS S

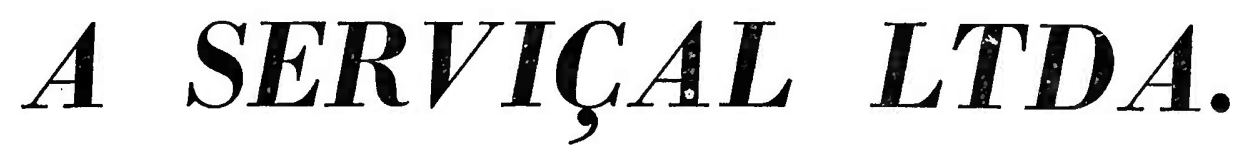

AgENCIAS REUNIDAS RIO DE JANEIRO E S. PAULO ,

Diretor Geral: ROMEU RODRIGUES

Marcas - Parentes e Licenças de Preparados Farmacêulicos - Comestiveis - Bebidas - Erc.

RIO DE: J A N EIRO

Rua São José n.० 49

$10^{\circ}$ Andar

CAIXA POSTAL, 3384

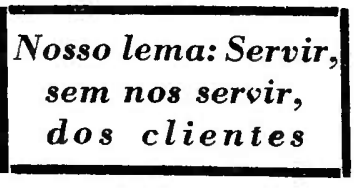

$\begin{array}{llllllll}\mathbf{S} & \tilde{\mathbf{A}} & \mathbf{O} & \mathbf{P} & \mathbf{A} & \mathbf{U} & \mathbf{L} & \mathbf{O}\end{array}$

Rua Direita, 64 - 3. ${ }^{\circ}$ And.

CAIXAS POSTAIS

3631 e 1421 